\title{
Twin anaemia-polycythaemia sequence or twin-to-twin transfusion syndrome? How to distinguish postnatally? A case report
}

\author{
Ewa Rojas Perez', Magdalena Kłosowska-Kwapisz², Paula Źródłowska³, \\ Marta Fiedorowicz-Kaźmierczak ${ }^{4}$, Witold Malinowski ${ }^{5}$ \\ ${ }^{1}$ Neonatology Department with Neonatology Intensive Care Unit, University Hospital in Zielona Gora, Poland \\ ${ }^{2}$ Department of Obstetrics and Gynaecology, University Hospital in Zielona Gora, Poland \\ ${ }^{3}$ Department of Haematology, University Hospital in Zielona Gora, Poland \\ ${ }^{4}$ Pediatrics Department, Faculty of Medicine and Faculty of Health Sciences, University in Zielona Gora, Poland \\ ${ }^{5}$ Department of Obstetrics and Gynaecological Nursing at the Faculty of Health Sciences, Pomeranian Medical University \\ in Szczecin, Poland
}

\section{ABSTRACT}

Twin pregnancy, especially monochorionic, is known to be a high-risk pregnancy, with a high morbidity and mortality rate. Complications that can occur in this type of twins are: twin-to-twin transfusion syndrome, twin anaemia-polycythaemia sequence, twin reversed arterial perfusion, or selective intrauterine growth restriction. Twin-to-twin transfusion syndrome is the most common complication and can affect 10-15\% of monochorionic twins. Twin anaemia-polycythaemia sequence is rarer and can be seen in $1-5 \%$ of this type of twin pregnancy. Sometimes it is very difficult to differentiate between these two syndromes because some symptoms can overlap. We present a case of monochorionic diamniotic twin pregnancy with an unremarkable course of pregnancy, which was ended prematurely at 33 weeks of gestation due to the onset of labour, complicated by twin anaemia-polycythaemia sequence diagnosed postnatally with a haemoglobin difference of nearly $20 \mathrm{~g} / \mathrm{dl}$.

\section{KEY WORDS:}

twin-to-twin transfusion syndrome, twin anaemia-polycythaemia sequence, monochorionic twins.

\section{INTRODUCTION}

Twin anaemia-polycythaemia sequence (TAPS) is a rarer complication dedicated to monochorionic diamniotic twin pregnancy, mostly seen after laser therapy, rarely occurring spontaneously. TAPS is caused by blood flow from the donor twin to the recipient twin by very small, arterial-vein anastomoses (A-V). Due to blood flow through small vessels in TAPS only haemoglobin discrepancy is observed [1]. TAPS needs to be differentiated from twin-to-twin transfusion syndrome (TTTS) because a haemoglobin difference can be seen in both syndromes [2]. The above-mentioned syndromes can be very severe complications and can lead to an unfavourable outcome of the pregnancy, causing the death of one or both foetuses.

We present a case of monochorionic twin pregnancy with an unremarkable course of pregnancy, premature-

\section{ADDRESS FOR CORRESPONDENCE:}

Ewa Rojas Perez, Neonatology Department with Neonatology Intensive Care Unit, University Hospital in Zielona Gora, 26 Zyty St., 65-046 Zielona Gora, Poland, e-mail: ewarojas@wp.pl 


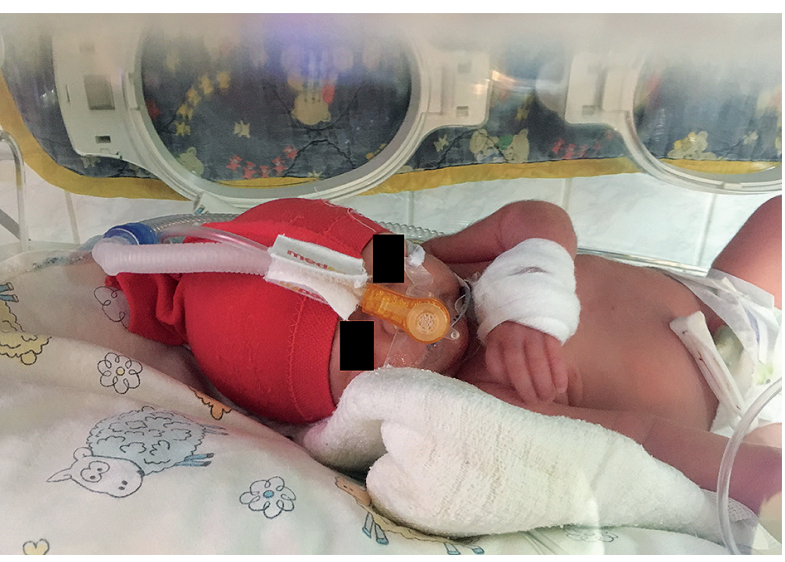

FIGURE 1. The donor twin

ly ended at 33 weeks of gestation, complicated by twin anaemia-polycythaemia sequence diagnosed postnatally.

\section{CASE REPORT}

A 36-year-old patient in second pregnancy spontaneously conceived a monochorionic diamniotic twin pregnancy (MCDA). No remarkable medical history was noted. The patient came for the first-trimester Down's syndrome screening test. The difference between crownrump length (CRL) was $10 \%$ and between nuchal translucency (NT) was 18\%; therefore, there were no signs of TTTS at this stage of the pregnancy. The risk for aneuploidies was low. Patient procedure was followed-up according to the MCDA twins protocol, which indicates a scan with full Doppler assessment every two weeks, to look for signs of TTTS, TAPS, or selective intrauterine growth restriction (sIUGR). Additionally, the cervical length was evaluated on every scan to predict preterm delivery. At 20 weeks, the cervix became shorter and vaginal progesterone commenced. At 23 weeks, in both twins, tricuspid regurgitation with normal contractility and anatomy of the heart was observed. The patient was admitted to the hospital at 25 weeks because further shortening of the cervix was noted. Steroids therapy was administered at 29 weeks because the cervix was $7 \mathrm{~mm}$ and there was high risk of preterm delivery. Throughout the whole pregnancy Doppler evaluation was normal, there were no signs of TTTS, TAPS, or sIUGR, and estimated foetal weight (EFW) discrepancy was between $2 \%$ and $4 \%$. The last ultrasound examination was four days before delivery and was normal with an EFW discrepancy of 2\%. Markers for TTTS and TAPS on each scan were checked on Foe-

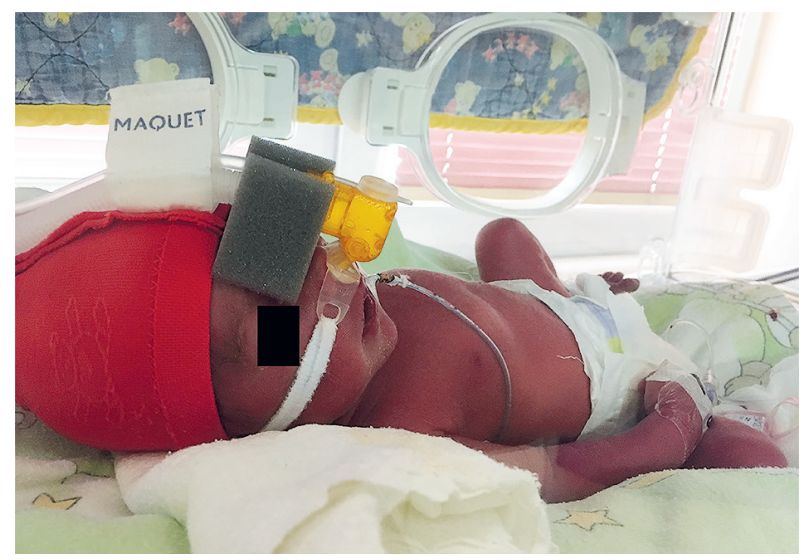

FIGURE 2. The recipient twin

tal Medicine Barcelona calculators for MCDA twins. The pregnancy was ended at 33 weeks by caesarean section because labour had started. The weight of twin one was $1825 \mathrm{~g}$ and Apgar score was 8-8-9-9 points (assessment was done in first, third, fifth, and tenth minute of life) and twin two was $1850 \mathrm{~g}$ and Apgar score was 6-8-8-8 points. On examination, twin one (donor twin) was very pale and had difficulties with breathing - gasping (Fig. 1). The neonate was admitted to the Neonatal Intensive Care Unit (NICU) and non-invasive ventilatory support was inaugurated. The neonate was haemodynamically stable. The blood test in the first day of life revealed deep anaemia with haematocrit (HCT) $27.3 \%$, haemoglobin (HGB) $9.43 \mathrm{~g} / \mathrm{dl}$, and red blood cells (RBC) $2.17 \mathrm{mln} / \mathrm{ul}$, and a blood transfusion was done (Table 1). The neonate was stable, and on day two non-invasive ventilatory support was stopped. Further tests and blood test were normal, no signs of infection were noted. Twin two (recipient twin) needed Neopuff from the second to the fifth minute of life. She was deep red in colour and had difficulties with breathing, shown as gasping and tachypnoea (Fig. 2). The neonate was admitted to the NICU, and non-invasive ventilatory support was started. A blood test on the first day of life showed polycythaemia with HCT $84 \%$, HGB $29.1 \mathrm{~g} / \mathrm{dl}$, and RBC $7.33 \mathrm{mln} / \mathrm{ul}$. Furthermore, poor peripheral perfusion, deep red hands and feet, and reduced activity of the neonates was observed. Further tests and markers of infection were normal. On the second day of life, non-invasive ventilatory support was stopped. As a result of deep polycythaemia, three blood reductions of $10 \mathrm{ml}$ each time were performed. Due to this procedure the haematocrit level was reduced to $64.9 \%$ (Table 2). Twenty-three days after delivery, the twins were dis-

TABLE 1. Blood tests - donor twin

\begin{tabular}{|l|c|c|c|c|c|c|}
\hline Day & RBC $(\mathrm{mln} / \mathrm{ul})$ & HCT (\%) & HGB (g/dl) & PLT (billion/l) & RDW (\%) & MCV (fl) \\
\hline 1. & 2.17 & 27.3 & 9.43 & 185 & 26.2 & 126 \\
\hline 7. & 4.4 & 42.9 & 14.9 & 385 & 30.4 & 97.6 \\
\hline 18. & 3.64 & 33.8 & 12.1 & 404 & 25.8 & 92.8 \\
\hline
\end{tabular}

$R B C$ - red blood cells, HCT - haematocrit, HGB - haemoglobin, PLT - platelets, RDW - red blood cell distribution width, MCV - mean cell volume 
TABLE 2. Blood tests - recipient twin

\begin{tabular}{|l|c|c|c|c|c|c|}
\hline Day & RBC $(\mathrm{m} \ln / \mathrm{ul})$ & HCT $(\%)$ & HGB (g/dl) & PLT (billion/l) & RDW (\%) & MCV (fl) \\
\hline 1. & 7.33 & 84.0 & 29.1 & 85.7 & 18.2 & 115 \\
\hline 2. & 5.44 & 63.2 & 22.0 & 111 & 18.3 & 116 \\
\hline 3. & 5.57 & 63.9 & 22.2 & 107 & 16.8 & 115 \\
\hline 7. & 5.78 & 64.9 & 23.1 & 104 & 16.7 & 112 \\
\hline 10. & 6.16 & 66.9 & 23.7 & 223 & 19.7 & 109 \\
\hline 11. & 6.05 & 65.7 & 23.3 & 254 & 20.3 & 109 \\
\hline 18. & 5.84 & 62.0 & 23.7 & 223 & 19.7 & 109 \\
\hline
\end{tabular}

RBC - red blood cells, HCT - haematocrit, HGB - haemoglobin, PLT - platelets, RDW - red blood cell distribution width, MCV - mean cell volume

TABLE 3. Haemoglobin discrepancy between twins

\begin{tabular}{|l|c|}
\hline Stage & Haemoglobin discrepancy between twins $(\mathbf{g} / \mathrm{dl})$ \\
\hline 1 & $>8$ \\
\hline 2 & $>11$ \\
\hline 3 & $>14$ \\
\hline 4 & $>17$ \\
\hline 5 & $>20$ \\
\hline
\end{tabular}

charged from the hospital, but a difference in HCT level was still observed.

\section{DISCUSSION}

TTTS can be seen in $10-15 \%$ of pregnancies and is the most common complication, which can occur in monochorionic diamniotic twin pregnancy [3]. TTTS is caused by foetal-to-foetal arterial-vein anastomoses (A-V) by which blood is flowing from one twin - the donor, to the other - the recipient. The donor twin is hypovolaemic and anaemic, and the recipient twin is hypervolaemic and polycythaemic [4]. The main criteria needed for prenatal diagnosis of TTTS is polyhydramnios-oligohydramnios sequence during the ultrasound examination. Depending on the advancement of haemodynamic changes, five stages of TTTS according to Quintero can be recognised. Doppler changes in umbilical artery and ductus venosus are observed in the third stage and above [5]. Some changes in myocardial contractility can also be seen in TTTS [6]. TAPS is a rarer complication and can occur spontaneously in 1-5\% of MCDA twins and in $2-13 \%$ of pregnancies after laser therapy [7]. TAPS is caused by blood flow from the donor twin to the recipient twin by very small, less than $1 \mathrm{~mm}, \mathrm{~A}-\mathrm{V}$, leading to a haemoglobin difference of more than $8 \mathrm{~g} / \mathrm{dl}$ [8]. Some authors suggest that TAPS is one of the forms of TTTS with haemoglobin discrepancy but without amniotic fluid differences [9]. In TAPS, due to slow blood flow from one twin to the other, foetuses have time to compensate by haemodynamic changes; therefore, amniotic fluid is normal $[7,10]$. An estimation was done after laser therapy, and through A-V anastomoses in TAPS 5-15 ml of blood could be transferred per day. A prenatal criterion of TAPS is the presence of discrepancy in middle cerebral artery peak systolic velocity (MCA-PSV) measured in MoM. In the donor twin high MCA-PSV (more than $1.5 \mathrm{MoM}$ ) is noted because anaemia is observed and in the recipient twin low MCA-PSV (less than 1.0 MoM) is present due to polycythaemia [11]. Furthermore, postnatal diagnosis of TAPS is based on haemoglobin discrepancy of more than $8 \mathrm{~g} / \mathrm{dl}$ and reticulocytosis ratio $>1.7$ or the presence of A-V anastomoses. TAPS is divided into five stages depending on the severity of the haemoglobin discrepancy (Table 3) [12].

Although in both TTTS and TAPS anaemia polycythaemia can be observed, this sequence is a diagnostic criteria only in TAPS. In our material, due to no signs of TTTS on the scan four days before delivery, we could exclude TTTS as a chronic event. After delivery, the initial diagnosis was made as acute TTTS. However, in our case an overload of the circulatory system was not seen and the haemoglobin discrepancy was much higher than $8 \mathrm{~g} / \mathrm{dl}$ $(19.67 \mathrm{~g} / \mathrm{dl})$ and met the criteria of TAPS stage 4 . Furthermore, because of the nature of the syndrome, in acute TTTS bone marrow activity markers (reticulocytosis, RDW [red blood cell distribution width]) are not present. However, we observed a difference in mean cell volume (MCV) between the twins: in the donor twin it was $126 \mathrm{fl}$ and in the recipient twin - $115 \mathrm{fl}$ (mean of MCV at 33 weeks was $115 \mathrm{fl}$ ). This discrepancy in MCV can be a reflection of the presence of reticulocytosis [13]. We also noted an RDW difference in this case: in the recipient twin $18.2 \%$ and the donor twin $26.2 \%$ (mean RDW at 33 weeks was $18 \%)$. Both parameters, MCV and RDW, are a reflection of activation of chronic haematopoiesis, which takes place in TAPS. Interestingly, thrombocytopaenia in the recipient twin can also be seen in TAPS. This is a result of excessive damage of platelets [14]. In our case, in the recipient twin, thrombocytopaenia was noted ( 85.7 billion/l), and in the donor, platelet level was normal (185 billion/l).

\section{CONCLUSIONS}

All of the above findings suggest that we had been dealing with advanced (stage 4) twin anaemia-polycy- 
thaemia sequence, despite initial impressions and the absence of prenatal signs.

\section{DISCLOSURE}

The authors declare no conflict of interest.

\section{REFERENCES}

1. Gucciardo L, Lewi L, Vaast P, et al. Twin anemia polycuthemia sequence from a prenatal perspective. Prenat Diagn 2010; 30: 438-442.

2. Lopriore E, Sueters M, Middeldorp JM, et al. Haemoglobin differences at birth in monochorionic twins without chronic twin-totwin transfusion syndrome. Prenat Diagn 2005; 25: 844-850.

3. Management of Monochorionic Twin Pregnancy. Royal College of Obstetricians and Gynaecologists. Green-top Guideline 2008; 51.

4. Lopriore E, Deprest J, Slaghekke F, et al. The outcome of Monochorionic diamniotic twin gestations in the era of invasive fetal therapy: a prospective cohort study. Am J Obstet Gynecol 2008; 199: 514-518.

5. Quintero R, Morales W, Allen M, et al. Staging of twin-to-twin transfusion syndrome. J Perinatol 1999; 19: 550-555.

6. Leszczyńska K, Preis K, Świątkowska-Freund M, et al. Comparison of fetal myocardial contractility before and after laser photocoagulation of communicating vesels in twin-to-twin transfusion syndrome. Ginekol Pol 2014; 85: 283-286.

7. Lopriore E, Middeldorp JM, Oepkes D, et al. Twin anemia-polycythemia sequence in twomonochorionic twins pair without oligi-polyhydramnios sequence. Placenta 2007; 28: 47-51.

8. De Villeirs S, Slaghekke F, Middeldorp JM, et al. Arterio-arterial vascular anastomoses in Monochorionic twin placentas with or without twin anemia-polycythemia sequence. Placenta 2012; 33: 227-229.

9. Umur A, Van Gemert MJ, Ross MG. Amniotic fluid and hemodynamic model in Monochorionic twin pregnancy and twin-to-twin transfusion syndrome. Am J Physiol Regul Intergr Comp Physiol 2001; 280: 1499-1509.

10. Lopriore E, van de Wijngaard JP, Middeldorp JM, et al. Assessment of feto-fetal transfusion flow though placental arteriovenous anastomoses in a unique case of twin-to-twin transfusion syndrome. Placenta 2007; 28: 209-211.

11. Slaghekke F, Pasman S, Veujoz M, et al. Middle cerebral artery peak systolic velocity to predict fetal hemoglobin levels in twin anemia-polycythemia sequence. Ultrasound Obstet Gynecol 2015; 46: $432-436$.

12. Slaghekke F, Kist W, Oepkes D, et al. Twin anemia-polycythemia sequence: diagnostic criteria, classification, perinatal management and outcome. Fetal Diagn Ther 2010; 27: 181-190.

13. Christensen RD. Neonatal Erythrocyte Disorders. In: Avery's Diseases of the Newborn. Elsevier 2018; 1152-1156.

14. Kaluba-Skotarczak A, Ropacka-Lesiak M, Drews K, et al. Zespół TAPS - nieznany i niedoceniany problem ciąż jednokosmówkowych. Ginekol Pol 2013; 84: 223-228. 